\title{
Infancia, familia y educación: análisis histórico y cambio social
}

\author{
Carmen M. Cerdá Mondéjar \\ Universidad de Murcia
}

Resumen

La atención y el interés por el cuidado y la educación de la infancia han ido variando a lo largo de las diferentes etapas históricas. Ligada a las transformaciones experimentadas en el seno de las familias, de forma gradual y progresiva la infancia ha ido alcanzando significado y relevancia en el medio social. La nueva función moral y espiritual asumida por la familia en el tránsito hacia los tiempos modernos, y que rebasaba su tradicional función como transmisora de apellido y patrimonio, implicó la aparición de nuevas emociones hacia los menores al tiempo que se intensificaba su individualidad.

En la actualidad la infancia adquiere notable centralidad tanto en el espacio privado familiar en el cual prima su protección, cuidado, asistencia y educación, enraizadas en nuevos vínculos de relacionabilidad (Burgess, 1972: 6-7), como también en el espacio público, social, político, normativo y económico. Partiendo de estas premisas, este artículo tiene por finalidad el estudio y análisis histórico de la concepción sobre la infancia y su educación, desde la antigüedad hasta nuestros días, dentro del marco de la familia y considerando las repercusiones que los cambios políticos, sociales, económicos, demográficos y culturales han tenido sobre la misma.

Palabras clave

Infancia; familia; educación; historia; cambio social

Códigos JEL: 120, 121, 125, 129

\author{
CHILDHOOD, FAMILY AND EDUCATION: HISTORICAL \\ ANALYSIS AND SOCIAL CHANGE
}

\section{Abstract}

The interest for the care and education of childhood have varied throughout the different historical time. Together with the transformations experienced within families, childhood has gradually and progressively attained meaning and relevance in the social environment. The new moral and spiritual function assumed by the family in the transition to modern times, and which went beyond its traditional function as transmitter of surname and heritage, implied the appearance of new emotions towards childhood at the same time their individuality intensified.

At present, childhood acquires important centrality both in the private family space in which its protection, care, assistance and education prevail, rooted in new link of relationship (Burgess, 1972: 6-7), as well as in the public space, social, political, normative and economic. With these ideas, this research aims to historical analysis of the conception of childhood and its education, from ancient times to the present day, within the framework of the family and considering the repercussions that political, social, economic, demographic and cultural changes have had on childhood.

Keywords

Childhood; family; education; history; social change

JEL codes: $120,121,125,129$

Fecha de recepción del original: 5 de mayo de 2021; versión definitiva: 16 de agosto de 2021.

Carmen M. Cerdá Mondéjar, Departamento de Teoría e Historia de la Educación. Universidad de Murcia, Campus Universitario de Espinardo. 30100 Murcia.

Tel.: +34 86888 3000; E-mail: cmcm@um.es; ORCID ID: https://orcid.org/0000-0003-2865-1801. 


\title{
Infancia, familia y educación: análisis histórico y cambio social
}

\author{
Carmen M. Cerdá Mondéjar \\ Universidad de Murcia
}

1. La difícil historia de la infancia

El campo de estudio de la historia de la infancia, así como sus diversos enfoques de investigación es relativamente novedoso. Surge superados los años 70 del pasado siglo XX y de forma lenta pero gradual, ha ido adquiriendo mayor interés en las últimas décadas, convirtiéndose en un área de investigación especializada, sobre todo a partir del surgimiento de la llamada Nueva Historia (Burke, 2003: 13). De forma coincidente, la expansión vertiginosa del universo de los historiadores e historiadoras, provocaría la proliferación de nuevos campos de investigación: la historia de la esfera privada, la historia de la vida cotidiana, de la vida familiar y de la mujer, y la historia del reciente giro "emocional", que situaba a la infancia como representación clara de un sentimiento de relaciones y sociabilidad propiamente moderno.

La historia, escribió Hobsbawm, no es únicamente un gran portal de acceso que "se debe atravesar para llegar a la realidad", es también "un elemento central de la realidad misma" (Hobsbawm, 2016: 45). Por ello, en el caso concreto que nos ocupa, la historia de la infancia se desarrollaba al mismo tiempo que se daba un doble proceso de visibilidad pública que implicó claramente la extensión y multiplicación de los sistemas e instituciones dedicados a su protección, reconocimiento, cuidado y participación ${ }^{1}$, y al carácter más centralista que adquiría a nivel familiar y social.

Con anterioridad, el auge de la historia social propiciado principalmente por la escuela francesa de Annales observó ya una transgresora forma de dialogar con el pasado. El mundo de la vida cotidiana o los protagonistas sin nombre ${ }^{2}$ de la historia comenzaron a adquirir relevancia

\footnotetext{
${ }^{1}$ Aunque el reconocimiento de la infancia se sitúa a finales de la Edad Moderna y desde antes existieron instituciones que velaban por su protección y cuidados, no será hasta tiempos recientes y amparados por el desarrollo legal que adquiere cuando su seguridad, salud y atención cobren un especial valor y sentido, haciendo del mismo modo avanzar los estudios sobre la misma.

2 En este caso de forma genérica la infancia prácticamente había sido irrelevante para la historiografía tradicional, únicamente "la historiografía francesa a través de figuras como Marc Bloch y Georges Lefebvre había hecho florecer la history from below, cuya pluma inaugural probablemente pueda atribuirse al "primero de los grandes historiadores de los de abajo", Michelet y sus estudios sobre la Revolución francesa" (Carrillo García, 2020: 137).
}

no como campos autónomos de investigación, sino dentro de análisis orgánicos de la compleja realidad social e histórica. Como había escrito Braudel dirigiéndose al auditorio del Collège de France en 1950 "evocando las palabras con las que Lucien Febvre había encabezado la fundación de la revista Annales d'histoire économique et sociale en el año de la Gran Depresión: el método y las interpretaciones de los hechos serían más provechosos si los intercambios intelectuales fuesen más frecuentes" (Carrillo García, 2020: 123). Así pues, las estructuras, instituciones, donde cabría incluir las familias como una vertiente más de la historia social, y sobre todo los procesos sociales que determinaban la vida de los individuos, con una visión más integradora que aumentaba la perspectiva temporal y que implicaba la ampliación de las fuentes de trabajo para conocer y acercarse al pasado, quebrantaban largos silencios historiográficos e iban adquiriendo notable relevancia. Poco a poco, los estudios sobre la historia de la infancia, como un elemento trascendental en las familias y como una etapa singular con su propia significación, interesaban a un mayor número de investigadores e investigadoras. Con todo, su desarrollo en el campo de la historia, a diferencia de otras áreas como la pedagogía, la antropología, la sociología y la psicología, fue laborioso. La historia de la infancia, escribió Egle Becchi, era "una historia difícil" (Becchi, 1983: 9). Ya en 1948 James H. S. Bossard llegó a afirmar en su libro The Sociology of Child Development que la historia de la infancia no se escribiría nunca por la escasez de datos históricos sobre la misma (1948: 548). Análogamente, Simonetta Ulivieri y Lloyd de Mause afirmaban que la gran dificultad para conocer la historia de la infancia radicaba en que no era tomada como objeto de examen histórico en sus condiciones reales de vida, sino que constituía una mera proyección de la vista de los adultos, es decir, los niños y niñas eran como sombras de los grandes temas de la historia. Mientras el hijo no era autónomo, pertenecía aún al mundo de los adultos en su condición de ser dependiente $y$, por tanto, no comenzaba a adquirir entidad propia. Mas taxativamente, si el niño no existía "con todas sus características infantiles, tampoco existía su historia" (Ulivieri, 1986: 48). Parecía que la inaccesible historia de la infancia fuese durante mucho tiempo como el sistema de la Sra. Pipchin en Dombey and Son de Dickens, consistente en "no animar a la mente de un niño a desarrollarse y expandirse como una flor joven, sino abrirla a la fuerza como una ostra". 
Durante la década de 1970, contando con el aporte metodológico braudeliano que observaba los acontecimientos de forma más particular y detallada y su impacto en diferentes niveles de análisis espacio-temporales, Jacques Le Goff y Pierre Nora acuñaron el término de Nueva Historia, arriba aludido. Esta reciente visión en el estudio de la ciencia histórica incluía como novedosa la llamada "nueva historia social" y el interés por nuevas facetas como la historia de las mentalidades surgida como un campo amplio, aunque quizá poco preciso, que incorporaba los comportamientos, los gestos cotidianos, el inconsciente, las emociones, las creencias populares, las formas de conciencia, las estructuras ideológicas o los imaginarios y cosmovisiones sociales, entre otros muchos elementos posibles de análisis. En todos ellos preexistía un marco histórico de la familia, adquiriendo además especial relevancia los procesos vitales de todos sus miembros, entre los que, de forma evidente, la infancia comenzaba a cobrar un valor esencial. Ciertamente la historia de la infancia no puede entenderse desvinculada de la historia de la familia y de la mujer. De la familia nuclear se pasaba a los estudios sobre "los lazos de parentesco y al ámbito del trabajo, de la educación y de las instituciones correctivas del comportamiento, en un intento por capturar la complejidad de los cambios individuales y familiares en el contexto del tiempo histórico" (Gonzalbo Aizpuru, 2006: 240). De este modo, los objetos de investigación y las fuentes se multiplicaban y todo aquello que ofreciese información sobre el pasado sería susceptible de ser utilizado como herramienta de análisis (Ginzburg, $1989)^{3}$. En otras palabras, la regeneración de la historiografía estaba inspirada, como habían escrito Jacques Le Goff y Pierre Nora en Hacer la Historia (1978), por "nuevos problemas, nuevos enfoques y nuevos temas"4. Así, la infancia se convertía en un elemento representativo de estudio histórico.

En este contexto fue pionera la obra, ya clásica, de Philippe Ariès L'enfant et la vie familiale sous l'ancien régime (1960) marcando un punto de partida importante en los estudios sobre la historia de la infancia. En el libro, el autor subraya el cambio de actitud de los adultos frente a la infancia a lo largo de la historia y visibiliza de forma clara cómo dichas transformaciones siguen operando en la actualidad de forma lenta y casi imperceptible para nosotros. Según Ariès, se había pasado de una sociedad polimorfa sumida en contrastes, en la que no había espacio para la infancia, en la que el niño aún sin ser capaz de valerse por sí mismo, vivía ya como un adulto en miniatura

\footnotetext{
3 Con todo, existen claras limitaciones importantes aplicadas a la historia de la infancia; los niños dejan relativamente pocos registros, en casos el de su existencia anotada en los libros de nacimientos y en otros, permanecen algunos restos materiales, como los juguetes. Sin embargo, es difícil conocer cómo los niños vivieron sus propias experiencias, las fuentes utilizadas no fueron hechas por los niños, pues nos han llegado mediadas por la visión del adulto, por tanto, la mayoría de historiadores de la infancia "pasan gran parte de su tiempo analizando los enfoques y las ideas de los adultos sobre los niños" (Stearns, 2010).

4 Este giro no ha estado exento de críticas. Como afirma Fontana "una cosa es que pensemos que una explicación histórica más rica debe incluir hoy muchos factores que anteriormente no tomábamos en cuenta, o que considerábamos complementariamente porque no éramos conscientes de su importancia, y otra que interpretemos eso como una invitación a abrir nuevos campos separados que tenderán a convertirse en la práctica en discursos independientes" (Fontana, 1992: 82).
}

en el espacio público ${ }^{5}$, a una sociedad más fragmentada que buscaba la intimidad y privatizaba la vida familiar y el crecimiento y desarrollo de la infancia haciéndola más vulnerable y dependiente, y asimilando un proceso reglado y formal de instrucción segregado por edades (Ariès, 1992: 212). Sin duda, este trabajo y la perspectiva aportada por el autor sirvieron de marco de referencia para otros estudios posteriores que, en principio, "profundizaban, respaldaban, matizaban o en casos contradecían las hipótesis y conclusiones de Ariès y que iban asentando una amplia base bibliográfica sobre el tema" (García Herrero, 1998: $226)^{6}$. En este sentido, hay que destacar el estudio del estadounidense Lloyd deMause (1974) que planteó su teoría evolutiva del cambio histórico basada en las relaciones paterno-filiales mantenidas en las sucesivas generaciones. Propuso así una periodización estilizada en función de las transformaciones producidas en las relaciones entre el adulto y el niño, denominando diferentes estadios históricos que, según el autor, evolucionan de forma casi lineal de lo negativo a lo positivo7. Un primer estadio sería infanticidio (antigüedad-siglo IV), seguido por abandono (siglos IV-XIII), después ambivalencia (siglos XIV-XVII); intrusión (siglo XVIII); socialización (siglo XIX a mediados siglo XX) y ayuda (mediado siglo XX en adelante).

Tanto Ariès como deMause coincidieron en situar el reconocimiento de la infancia durante la Edad Moderna, concurriendo con la aparición de instituciones protectoras que planificaban el cuidado, la supervisión y la formación de la generación más joven (Finkelstein, 1986: 20). Sus investigaciones, fundamentales como punto de partida en tanto planteaban la convergencia entre la historia de la infancia y la historia de la educación, estudiaron la infancia tratando de darle entidad como sujeto histórico y social. De este modo, la mayoría de los primeros trabajos sobre la historia de la infancia surgidos en los años sesenta y sobre todo setenta, al amparo de los ya citados, cargados quizá de excesiva sociología según la moda de la época, se centraron principalmente en la evolución de las instituciones educativas. Estas eran concebidas, en unos casos, como un medio de control social, adoctrinamiento y disciplina $y$, en otros, como instituciones de preparación-capacitación orientadas a un desempeño económico futuro, e incluso como espacios de protección al menor y nicho de oportunidades; sin embargo, raramente se centraban en el

\footnotetext{
5 Sobre la complementariedad entre el crecimiento y el aprendizaje del niño en sus primeros años de vida como un acto público que se desenvolvía en espacios donde la comunidad siempre estaba presente, y como un acto privado reducido al ámbito familiar, Gélis realiza un interesante estudio defendiendo la idea del distinto equilibrio de ambas esferas según el momento histórico (2005: 306).

${ }^{6}$ Cabría destacar, por ejemplo, el número monográfico "Enfant et Sociétés" de la revista Annales de Demographie Historique publicada en 1973; La clásica obra de LI. de Mause, Historia de la infancia, cuya primera edición es de 1974 y L'enfant, Recueils de la Société de Jean Bodin publicada en 1976 y que dedica su segunda parte a la Europa medieval y moderna. Por su parte Lawrence Stone criticó el enfoque unilineal de la obra de Ariès contrario a los hechos conocidos y la vaguedad de la cronología y el espacio geográfico (1986: 251, 252).

7 No obstante, estas etapas no se anulan en las diferentes épocas, conviven, aunque las más primarias tienen una frecuencia menor. Esta visión de evolución lineal de la historia de la infancia ha sido utilizada con una mirada algo simplista, a nuestro juicio y "extravagante" a ojos de Cunningham (1999) para analizar la historia de determinados fenómenos como la violencia, el abuso, la explotación o el abandono de los niños, vistos como fases de la historia de la humanidad que evolucionaban hacia un mundo feliz sin considerar los acontecimientos externos (Stone, 1986).
} 
mundo de las "ideas, procesos o sensibilidades" propios de la infancia a lo largo de la historia (Finkelstein, 1986: 22). En general y sin dejar de lado otros trabajos aparecidos en el ámbito pedagógico afín a teorizar sobre educación, didácticas y escolarización, y psicológico abordando sus aspectos fisiológicos y psicológicos en evolución (Delval, 1988), el concepto de infancia aparecía en casi todos como una categoría general e históricamente imprecisa (Ulivieri, 1986: 48); y es que hasta hace bien poco, como decía lacónicamente Escolano, la infancia ha sido un objeto de análisis poco frecuentado por los historiadores $(1980)^{8}$.

Únicamente con el avance y revisión de los estudios sobre la historia de la familia y sobre la historia de la mujer, propiciados por una mayor interdisciplinariedad y un interés más particular por la esfera privada y lo cotidiano, donde las formas de relación familiares, los modos de vida de la gente común y la condición femenina en todas sus facetas y dimensiones, adquirían relevancia, se lograba ampliar el campo de conocimiento sobre la historia de la infancia y su existencia, tanto dentro de la familia como en su correspondencia con las diversas estructuras sociales. Sin duda y en acuerdo con Escolano, estos avances en las investigaciones permitían un mejor conocimiento del carácter y la personalidad de cada momento histórico, "el análisis de las mentalidades colectivas, es decir, de las actitudes ante el mundo, la vida, la familia, la infancia, el sexo y la escuela, entre otros temas de la vida social, ayuda también a comprender y explicar el ethos que impregna la educación de una época y de un tipo determinado de sociedad" (Escolano, 1997: 71).

A nivel internacional el campo de estudio de la historia de la infancia ha ido ganando terreno, aunque lógicamente ha experimentado un desarrollo desigual a nivel geográfico. Los estudios pioneros se publicaron principalmente en Europa Occidental y en Estados Unidos; a ello contribuyó la aparición de publicaciones especializadas tales como Journal of the History of Childhood and Youth, órgano difusor oficial de la Society for the History of Children and Youth (SHCY). Por su parte, es interesante la evolución que para el caso concreto de España y en los últimos treinta años, se ha dado en cuanto a las temáticas de investigación en historia de la infancia ya que, si en principio aparecía más ligada a la historia de la familia, poco a poco ha ido configurándose como un campo autónomo, aunque vinculado a otros temas. Así, cabe citar, la historia de la infancia y mortalidad infantil, historia de la infancia y medicina, historia de la infancia y trabajo infantil, historia de la infancia y escolarización, historia de la infancia y abandono infantil, historia de la infancia y delincuencia, historia de la infancia

\footnotetext{
${ }^{8}$ En noviembre de 1979 se celebró en la Universidad de Salamanca la Semana de Infancia y Universidad, organizada por el Departamento de Educación Comparada e Historia de la Educación fruto de la cual se presentó el número 6 de la revista Studia paedagogica, de ciencias de la educación. Entre los trabajos más significativos se destacaron los de Agustín Escolano Benito sobre las concepciones de la infancia a lo largo de la historia, de Antonio López Eire sobre el niño en la antigüedad clásica, de José Luis Martín que abarcaba el período de la infancia durante la Edad Media, de Luis S. Granjel sobre el niño en la historia de la medicina, un análisis jurídico de Francisco Tomás y otro en el que se abordaba la infancia en el contexto de la naturaleza y la educación medioambiental, de José Manuel Gómez Gutiérrez. También cabe reseñar la publicación del monográfico sobre historia de la infancia y de la juventud por la Revista de Educación en el último trimestre de 1986. En el mismo se incluyen entre otros trabajos de P. Ariès, B. Finkelstein y S. Ulivieri citados a lo largo de estas líneas.
}

y modernidad, historia de la infancia y desarrollo psicológico y deficiencias, historia de la infancia y mundo antiguo y edad media, historia de la infancia y derecho, historia de la infancia y literatura, historia de la infancia e historia local... (Alzate Piedrahita, 2004) ${ }^{9}$. Naturalmente, a esta mayor profusión de trabajos e investigaciones sobre la historia de la infancia ha contribuido la especialización de determinadas materias en el ámbito académico. Una especialización que, como afirmó elocuentemente Hobsbawm, puede ser afortunada siempre que las nuevas historias no sean depositadas en "contenedores que no se comunican entre sí" (Hobsbawm, 2014: 276).

Además, este nuevo panorama en los estudios sobre historia de la infancia, así como el creciente interés de los investigadores e investigadoras de las ciencias sociales en general hacia este campo historiográfico, ha conllevado un replanteamiento de cuestiones relacionadas con el impacto que sobre los niños y niñas tuvieron los grandes procesos históricos de cambio social, político, económico y cultural. En este sentido, cabe destacar los trabajos de Hugh Cunningham (1999) sobre las interacciones entre el desarrollo económico, las políticas públicas, los imaginarios colectivos y las formas de vida de la infancia. Sin embargo, el anhelo de una perspectiva dialéctica, como la que ofrece Cunningham, con demasiada frecuencia se ha visto confrontado con los límites autoimpuestos por los convencionalismos académicos (Carrillo García, 2020). Por ello, se precisa superar las tradicionales periodizaciones históricas y observar en la infancia y su contexto los efectos de los cambios sociales à la Braudel cuya perspectiva longue durée contribuirá a ampliar nuestra comprensión sobre la construcción y significado actual de esta edad de la vida. Porque, evidentemente, la imagen y el significado de la infancia han variado en cada época histórica. La periodización de diferentes etapas en el crecimiento y desarrollo humano es un hecho relativamente reciente ${ }^{10} \mathrm{y}$ depende de forma clara de la concepción ideológica dominante de cada sociedad y momento histórico.

En lo que sigue, rebasando el marco de las comunidades primitivas y circunscritos al ámbito europeo por las limitaciones espacio temporales que plantea el propio estudio, se aborda en primer lugar, a partir de las fuentes conservadas, el significado de la infancia en las culturas clásicas, para las cuales este período no era más que una

\footnotetext{
${ }^{9}$ Como se ha anotado el campo de estudio de la historia de la infancia se ha desarrollado de forma intensa en los últimos años y citar todas las publicaciones aparecidas sería tarea laboriosa. Referimos aquí por su significación la publicación en 2005 "La infancia en la historia: espacios y representaciones", coordinada por Luis María Naya Garmendia y Paulí Dávila Balsera, que recogía las comunicaciones presentadas al XIII Coloquio de Historia de la Educación.

${ }^{10}$ Ya en el siglo V a. C. Hipócrates clasificó la vida del hombre en diferentes etapas en función del número 7 al que se atribuían propiedades mágicas, así: 0-7 bebé, 7-14 niño, 14-21 adolescente, 21-28 hombre joven, 28-49 hombre maduro, 49-56 hombre de edad y más de 56 anciano, recogidas por Isidoro de Sevilla en sus Etimologías, quien manteniendo dichos períodos amplió la adolescencia hasta los 28 , la juventud hasta los 50 y la madurez hasta los 70 . No obstante, esta clasificación responde más a una división numérica y descriptiva que a una separación de ciclos de desarrollo vital, como se concebirá mucho más adelante. Se observa sin embargo cómo al aumentar la esperanza de vida se alargaron también los ciclos vitales. En este sentido argumenta Ariès que estos períodos quizá estuvieron mucho más presentes en el mundo greco romano que durante la Edad Media (Ariès, 1992: 10) donde las "edades de la vida" humana se vinculaban con el ciclo de las estaciones. Incluso había periodizaciones que vinculaban las edades vitales con los planetas y con los signos del zodiaco.
} 
etapa de transición de la vida que pasaba rápidamente; el niño únicamente se diferenciaba del adulto en su estatura. Durante los siglos siguientes, favorecidos por algunos períodos de paz y sobre todo por una nueva organización jurídica de la sociedad, se evidenciaron cambios en las formas de pensar y en las sensibilidades, junto a la permanente falta de significado como una edad propia y singular, la infancia adquirió relevancia como garante de la descendencia. Posteriormente, con la llegada de la modernidad, la consolidación de la mentalidad burguesa y el auge de una sociedad más individualizada, el universo infantil fue adquiriendo una serie de singularidades sociales y familiares diferenciales con respecto a tiempos anteriores. Sin embargo, solo cuando las asombrosas transformaciones de las sociedades contemporáneas produzcan cambios tan amplios y profundos que el pasado aparente ser una nebulosa, la infancia se reconoce plena y específicamente como tal y adquiere relevancia y centralidad en el contexto familiar y social.

\section{Las edades de la Infancia}

2.1. Infancia y aprendizaje para la vida adulta: educar al niño para no castigar al hombre

La máxima de orden moral educar al niño para no castigar al hombre atribuida al matemático y filósofo griego Pitágoras reflejaba de forma clara un sentido interés por la educación y la crianza de la infancia y la consiguiente niñez, y su concepción, como un período preparatorio para la vida adulta, sin más importancia que la de un tránsito natural y consustancial al curso de la existencia humana, desde el nacimiento a la muerte. Era la de la infancia una etapa libre y ufana, sin excesivas atenciones y sin ser considerada una fase propia y específica del desarrollo humano con sus cualidades y características, tal como la entendemos actualmente.

Los famosos héroes homéricos del antiguo mundo griego, más legendarios que reales, eran adultos sin infancia, "irrumpen en su pequeña historia colectiva desde la muchachez, nunca desde la infancia" (Delgado Criado, 1998: 26). Para el caso espartano, el Estado, fuerte y poderoso, premiaba e incentivaba la natalidad, mediante la exención de la movilización militar y de impuestos a las familias (Delgado Criado, 1998: 27). De igual modo, aprobaba el infanticidio en caso de que el menor no naciese apto para la lucha, pues su grandeza radicaba precisamente en su fuerza en la batalla. En general, son escasos los testimonios conservados que nos ofrecen datos y recomendaciones sobre el período anterior a los seis años; los conserva- dos, además, ofrecen un reflejo sesgado de la infancia en tanto no contemplan la sociedad en su conjunto. Esta falta de información que afecta básicamente a los niños y niñas más pobres y desamparados, reduce la mirada lanzada al pasado y limita el análisis histórico a una mera consideración generalista y especulativa sobre las edades de la infancia en los distintos períodos.

Sobre la infancia en la Grecia clásica, Platón en una de sus últimas obras de madurez recomendaba que hasta los dos años el niño se mantuviera lo más cercano posible a la madre y a partir de los tres años sugería estimularlo con juegos y entretenimientos, gimnasia para el cuerpo y música para el alma (República, VII: 23). La educación era para Platón "el instrumento necesario para formar al hombre" (Ballén Molina, 2010: 36). Su discípulo, el estagirita Aristóteles en el libro IV de Política también abordaba la educación en la primera infancia y la importancia de estimular su crecimiento recomendando una buena alimentación, una atención a sus primeros movimientos y una cuidada adaptación a las condiciones climáticas (Capítulo XV, Libro IV). El juego, además, era esencial en esta etapa de la vida para excitar la actividad fisiológica y preparar al niño para los futuros trabajos a que habría de dedicarse con esfuerzo en edad más avanzada. Igualmente, Crisipo de Solos aun concediendo tres años para el cuidado por parte de las ayas, apuntaba que éstas debían ir formando el entendimiento del niño con los mejores conocimientos. Las niñas, de las que poco se sabe a excepción de algunos ejemplos notables, eran claramente educadas en el ámbito doméstico por las madres y su prestigio dependía de la escala de valores masculina ${ }^{11}$.

Por su parte, y con una notable diferencia cronológi$\mathrm{ca}$, el hispanorromano Quintiliano en su obra Instituciones Oratorias diferenciaba tres etapas en el desarrollo de la infancia y en la formación de un "buen orador": desde el nacimiento a los tres años, edad en la que el niño aprendía a hablar y era imprescindible la enseñanza de un lenguaje correcto que no hubiese "que desenseñarle" (Capítulo I.I); de los tres a los siete años, cuando el niño estaba todavía en casa pero debían establecerse actividades que le entretuvieran y motivasen su aprendizaje, pues no debía desaprovecharse en nada esta edad. De hecho, refiere las bondades del juego con figuras de las letras hechas de marfil, o cualquier otro material, "por el cual hallen gusto en manejarlas, mirarlas y señalarlas por su nombre" (Capítulo I.IV). Por último, la etapa de los siete años a la adolescencia, en la cual debía enviarse a los niños a la escuela; lugar que "aprovechará con ver reprender la pereza de unos, y alabar la aplicación de otros: con las alabanzas cobrará emulación; tendrá por cosa vergonzosa quedar atrás de los iguales, y por honra exceder a los mayores" (Capítulo II.II). Además, en sus múltiples escritos el hispanorromano defendió un modelo de enseñanza individualizado, censuró

\footnotetext{
11 Las mujeres durante el Alto Imperio mantuvieron la condición social de sus padres o maridos. Fue significativo el modelo de la "materfamilias" donde cabría señalar el caso de la matrona docta, con ejemplos como el de Cornelia, que representaba un modelo de maternidad alternativo que, sin descuidar los cuidados se encargó también de la formación de sus descendientes hasta una edad avanzada. Otro modelo, más controvertido, sería la puella docta, cuyas connotaciones variaban en lo relativo a la clase social y el estilo de vida. Igualmente, para épocas posteriores existieron mujeres cultas que destacaron por sus virtudes como educadoras.
} 
los castigos y abogó por un aprendizaje estimulador. Quizá fue Quintiliano, influido por Cicerón ${ }^{12}$, de los pocos autores defensores de la educación desde los primeros años y garante de considerarla como un proceso que dura toda la vida, nullus tempus vacare cura (que ninguna edad carezca de educación), tratando de poner orden en un mundo lleno de contradicciones y paradojas.

Es sabido que la cultura romana mostró algunas prácticas, incomprensibles a nuestro juicio, y que con el tiempo se fueron abandonando. Afectaban sobre todo a la infancia no reconocida, tales eran la aprobación del infanticidio, los abortos indiscriminados, la práctica de vendar a los niños hasta los dos años ${ }^{13}$ y la autoridad omnisciente del paterfamilias amparada por la ley de las Doce Tablas (Delgado Criado, 1998: 43).

También y junto a ello, tanto en Grecia como en Roma existieron genios o divinidades protectoras de la infancia, aun siendo ésta, como se ha expuesto, una edad considerada de forma relativa en tanto necesaria superar cuanto antes. En la mayor parte de casos, tras el momento en que terminaba el período de la infancia, esto es, hacia los seis o siete años, la madre se inhibía de forma natural del proceso de su educación, confiándola al pedagogo en caso de familias ricas o, en casos de gentes de más baja condición social, enviando a los hijos a cualquiera de las numerosas y bulliciosas escuelas primarias que algunos profesionales de la educación abrieron en varias ciudades a partir del siglo II (Carcopino, 1993) ${ }^{14}$.

Estas referencias anotadas y los consejos otorgados por tan sabios filósofos no prescindían de la idea general de concebir la infancia como un período en formación hacia la vida adulta, hacia la conformación del ciudadano, enmarcado en el espacio público y sin entidad sustancial. No obstante, esta concepción de relativa invisibilidad de la infancia, no debe entenderse desvinculada de las funciones básicas de la reproducción familiar. Independientemente de la adscripción social (aunque era y es determinante), la descendencia biológica, la continuación del linaje, o los recursos materiales de la familia a los que inexorablemente contribuían niños y niñas, y que aseguraban la atención y los cuidados de sus progenitores cuando envejecían, constituían los elementos funcionales de la reproducción familiar y social. De este modo, los descendientes aparecen como un bien necesario, aunque por diferentes motivos, según cada caso y cada época, ya que "sobre ellos recae una mirada cargada de expectativas, de forma que se les valora por lo que llegarán a ser, a hacer y a proporcionar,

\footnotetext{
12 En su tratado Del Orador manifestó la necesidad de que cada maestro conociese la naturaleza de cada uno de sus alumnos.

13 El fajamiento como práctica de crianza para evitar deformaciones en los miembros y conservar el calor corporal y como técnica de prevención y protección de la salud, ha estado muy extendido hasta tiempos recientes en diversas comunidades del área andina existiendo numerosas evidencias documentales de su profundidad histórica y su vigencia en áreas indígenas de Perú y Bolivia. Si bien actualmente está cada vez más en desuso, las madres continúan envolviendo a los bebés con varias mantas y cubriendo sus cabezas, ante la necesidad de proteger al bebé debido a su extrema vulnerabilidad (Remorini, 2013: 421).

14 Aunque para la fundación de la primera escuela pública hubo aún que esperar hasta el mandato de Teodosio II, Código Teodosiano, VI, I, I. Además, era importante diferenciar al niño esclavo de aquel que pertenecía a una familia acomodada. El primero trabajaba más y recibía una educación más limitada, el segundo gozaba de privilegios propios de su condición social (Martínez Ruíz Funes, 2013: 48)
}

pero no es tan evidente que se les estime simplemente por lo que ya son, hacen y proporcionan" (García Herrero, 1998: 65).

2.2. Infancia ambivalente, entre la inconsciencia, la educación en común y el deseo de perpetuación familiar

Durante el posterior y largo período de la Edad Media y hasta bien avanzados los tiempos modernos, prácticamente no varió la concepción de la infancia pues se mantuvo su invisibilidad y su inconsciencia como una etapa específica del desarrollo humano diferenciada de la niñez y la adolescencia (Ariès, 1992). Tampoco se daba una preocupación excesiva y trascendente por dicho período, más allá de otorgar los cuidados necesarios ante su evidente fragilidad y contemplarlo en su proyección hacia el futuro. Se puede considerar, no obstante, que en el marco de la gran influencia ejercida por el cristianismo, se dignificó la figura del niño al atribuirle caracteres específicos como la sencillez, la bondad y la inocencia y proclamar valores tales como la dignidad, el respeto o el cariño en el marco conyugal, ahora sacralizado como unión indisoluble. De igual modo con la incorporación de los sacramentos religiosos, se reconoció la existencia del alma infantil y su inmortalidad lo cual confería nuevo carácter a su existencia y a su fallecimiento. Mucha de la literatura cristiana otorgó gran importancia a la primera educación y al papel desempeñado por las familias.

Ya para el siglo XIII propiciados por un período de cierta paz y una nueva organización jurídica de la sociedad, se evidenciaron cambios en las mentalidades y en las sensibilidades; se mantuvo con todo una cierta ambivalencia reflejada entre la citada falta de significado y la relevancia que adquirió la descendencia en este período.

En un tiempo en el que para la inmensa mayoría de la población solo el trabajo garantizaba la supervivencia, los hijos e hijas, si eran "buenos" y sabían cumplir como tales, proporcionaban seguridad y tranquilidad en la etapa final de la vida [...] para las mujeres y hombres de finales de la Edad Media tener hijos, sobre todo varones, era muy importante, incluso motivo de fiesta y regocijo, aunque ello no implicaba necesariamente que se les apreciara y valorase siempre como tales (García Herrero, 1998: 64).

La familia mantuvo sus funciones de reproducción básicas, adecuadas al nuevo contexto histórico, esto es, conservación de bienes, procreación, continuidad, práctica de un oficio común, ayuda mutua, seguridad y protección del honor. Sin embargo, es más cuestionable que se reprodujeran sensibilidades afectivas, al menos no como serían concebidas con posterioridad. Como expresaba Ariès: "el sentimiento no era indispensable para la existencia" (Ariès, 1992: 11), naturalmente "los padres y adultos del pasado 
no carecían de amor hacia los hijos, pero les faltaba la madurez emocional necesaria para ver al hijo como persona" (Ulivieri, 1986: 62) al menos quizá, en el marco doméstico familiar más íntimo. La familia se hallaba todavía integrada dentro de las solidaridades amplias propias del linaje y la vecindad (Fontana, 1999: 55) y de este modo, la atención hacia la infancia se desenvolvía mayoritariamente en el espacio público que era donde el niño iniciaba su andadura hacia la vida adulta. Era un mundo social en el que las estructuras y actividades humanas estaban delimitadas por la solidaridad mecánica, tal como lo entendió Durkheim. Hechos tales "como el nacimiento, el casamiento y la muerte tenían una dimensión colectiva, con prácticas y ritos de amplia participación social" (Fontana, 1999: 55). El aprendizaje durante la infancia suponía una forma de educación en común, "un conjunto de influencias que convertían a cada ser en producto de la colectividad y que preparaban a cada individuo para el cometido que de él se esperaba" (Gélis, 2005: 296) ${ }^{15}$. Aunque existió aparentemente una preocupación intelectual por la educación de los niños y niñas como lo demuestra la proliferación de tratados sobre el tema, en el terreno más mundano, dicha educación dependió del estamento social al que se pertenecía, lo que naturalmente evidenciaba las notables diferencias desde cualquier perspectiva entre unos grupos sociales y otros. Las extraordinarias diferencias que dependían de los principios generales de las estructuras normativas de las sociedades precapitalistas se veían reflejadas en las múltiples infancias y en su destino existencial. Basta citar la brecha que separaba a los hijos legítimos de los ilegítimos, los niños de las niñas, los niños blancos y los niños de color; por supuesto, entre el popolo grasso y el popolo minuto, entre niños con reconocimiento familiar y niños expósitos, todo lo cual nos lleva a considerar la existencia de varias infancias, o por lo menos, de formas muy distintas de vivir la infancia. Con la división del trabajo y el auge de las solidaridades orgánicas durante el capitalismo, la desigualdad social y particularmente las formas de entender la infancia adquirirán una nueva fisonomía.

En general, durante gran parte del Medievo y debido a la preeminencia de una sociedad feudal y una economía básicamente agrarias, la conciencia del ciclo de vida se relacionaba de forma directa con las estaciones, era por tanto circular y el hecho de que la mortalidad infantil fuese alta, únicamente preocupaba en la medida de saber que a la

\footnotetext{
15 Sobre el aprendizaje en el seno de la comunidad presente desde las primeras comunidades primitivas anotaba Aníbal Ponce "la enseñanza era para la vida por medio de la vida [...] Si los padres dejaban a los niños en completa libertad, ¿cómo todos los adultos resultaban después idénticos? Si no existía ningún mecanismo educativo especial, ninguna "escuela" que imprimiera a los niños una mentalidad social uniforme, ¿en virtud de qué, la anarquía de la infancia se transformaba en la disciplina de la madurez? Estamos tan acostumbrados a identificar la Escuela con la Educación y a ésta con el planteo individualista en que intervienen siempre un educador y un educando, que nos cuesta no poco reconocer que la educación en la comunidad primitiva era una función espontánea de la sociedad, en un conjunto a igual título que el lenguaje o la moral. Y así como resulta evidente que el niño no debe concurrir a ningún instituto para aprender a hablar, debe resultarnos no menos evidente que en una sociedad en la cual la totalidad de los bienes están a disposición de todos, puede bastar la silenciosa imitación de las generaciones anteriores para ir llevando hacia un mismo cauce común las inevitables desigualdades en los temperamentos" (2015: 45). Para el autor argentino en el momento en que la sociedad pierde su primitivo carácter comunitario y se organiza de forma jerárquica, primero por estamentos y posteriormente por clases sociales, la educación se vuelve dogmática, sistemática y desigualmente organizada.
}

muerte sucede la vida y al tiempo es precedida por ésta. La "Edad Media utilitaria", como escribió Jacques Le Goff en $L a$ Civilización del occidente medieval, "no tiene tiempo para apiadarse o maravillarse ante el niño, a duras penas alcanza a verlo". El niño es un "adulto pequeño" que en cuanto sale del espacio de la madre, se entrega a las "fatigas del trabajo rural o del aprendizaje militar" (Le Goff, 1999: 259).

\subsection{Educar todo, a todos y totalmente, hacia una nueva educación}

En el Renacimiento el auge de la individualidad y del personalismo revivió, al menos teóricamente, el ideal de que cada persona es distinta y sus diferentes capacidades y aptitudes podían (y debían, evocando a Aristóteles) llegar a perfeccionarse mediante una nueva educación. El individuo adquiere valor, se convierte "en la medida de todas las cosas" y se le reconoce una personalidad propia; no es casual que a partir de ahora los grandes artistas renacentistas dejasen de ser artesanos anónimos y se esforzasen por imprimir en sus obras su propio estilo artístico. De forma progresiva y sin poder determinar una fecha concreta "el cuerpo individual se desgaja(rá) simbólicamente del gran cuerpo colectivo", el espacio poco a poco torna en privado y el niño paulatinamente se hará visible, adquiriendo singularidad y un puesto determinante en las preocupaciones del padre y de la madre (Gélis, 2005: 298).

El humanismo reforzó estas ideas y defendió la educación completa de la persona y el desarrollo íntegro y simultaneo de las tres facetas de perfección humana: mente, cuerpo y espíritu, recuperando el clásico ideal platónico. Así, por ejemplo, François Rabelais y Michel de Montaigne, críticos con ciertas formas clasistas de la enseñanza de su época, "proponían centrar el interés social en una formación integral del ser humano, incluida la hasta entonces ignorada dignidad del niño" (Morente Mejías, 2012: 242). Defensores de estas tesis sobre la importancia de la educación, de la consideración de la infancia y de las capacidades de cada cual como personas únicas e irremplazables fueron importantes pensadores tan variopintos como el obispo Rodrigo Sánchez de Arévalo, el humanista Antonio de Nebrija, Erasmo de Rotterdam, Juan Luis Vives o el médico Huarte de San Juan, entre otros muchos. Todos compartían la idea de que educación era vital desde los primeros años de vida, sin distinciones, únicamente las impuestas por las propias cualidades de cada uno; $y$, por supuesto, la madre desempeñaba en ello un papel fundamental, tanto en la alimentación ${ }^{16}$ como en el ánimo y el estímulo. Este interés intelectual sobre la infancia supuso el inicio de una actitud más compasiva hacia la misma, sobre todo hacia los niños y niñas abandonados o huérfanos acogidos ahora en nuevas instituciones de beneficencia

\footnotetext{
16 Se destacó el valor de la lactancia materna ofrecida directamente por la madre subrayando sus aspectos positivos tanto para la salud del bebé, como para fomentar el sentimiento de apego.
} 
públicas que fueron surgiendo de forma progresiva por las principales ciudades europeas ${ }^{17}$. De forma paralela a esta nueva mentalidad, sucede una conciencia más lineal de la existencia humana, primero en las grandes ciudades y entre las clases más acomodadas, y mucho más gradual en el campo y entre los sectores sociales más pobres. Es innegable que esta nueva conciencia sobre el principio y el fin de la vida, desde al nacimiento hasta la muerte, vino determinada por las asombrosas transformaciones que desde cualquier perspectiva se estaban produciendo en el mundo occidental: el cambio demográfico, el apogeo de las ciudades, el desarrollo de la burguesía, el auge de actividades comerciales y mercantiles $y$, por supuesto, el reforzamiento del poder de los estados.

Con todo, la grave crisis política, económica, social y religiosa del siglo XVII con diferentes repercusiones en los distintos países europeos, implicó un aumento de las cifras de mortalidad infantil y del número de niños abandonados; el carácter personal se volvió más pesimista y melancólico y, en cierto modo, junto al mencionado interés por la infancia entre las clases altas e instruidas de la sociedad, el niño continuó ocupando un lugar subordinado en el devenir cotidiano ${ }^{18}$. Como atestigua gran parte de la tradición oral de la época recogida después por los grandes escritores de cuentos clásicos, el universo infantil es infortunado, accesorio e insignificante para los adultos, habitado por malvadas madrastras y huérfanos, excesivas crueldades y emociones reprimidas y brutales.

En el ámbito pedagógico, como consecuencia del contexto esbozado e inspirado por la renovación metodológica de Descartes, se realizaron esfuerzos por aplicar un nuevo método a la enseñanza que fuese "capaz de discriminar la diferencia en el modo de ser de cada uno y de transmitir con eficacia los conocimientos" (Delgado Criado, 1998: 127). Las palabras de Comenio, considerado padre de la pedagogía moderna, expresaban bien este pensamiento cimentado en la razón, el empirismo y el universalismo: "educar todo, a todos y totalmente". En su Didáctica Magna (1632) afirmaba con la debida causticidad: "Quede, pues, sentado que a todos los que nacieron hombres les es precisa la enseñanza, porque es necesario que sean hombres, no bestias feroces, no brutos, no troncos inertes" (Comenio, 1998: 17). Pero las aspiraciones teóricas del padre de la didáctica moderna estaban muy alejadas de la realidad existencial del común de los mortales. De hecho, sus anhelos cimentados en una educación de todos los niños desde los primeros años de vida, sin distinción del grupo social, la importancia de un buen ambiente familiar o su interés por el desarrollo físico y psíquico, no adquirieron relevan-

\footnotetext{
17 A este respecto un completo trabajo sobre nuestro país puede consultarse en Félix Santolaria Sierra (1997). Atentos a la infancia más desfavorecida y manteniendo una postura piadosa, en casos más caritativa que instructiva, destacaron las obras de los religiosos José de Calasanz, Juan Bautista La Salle y Vicente de Paúl.

18 El jesuita Baltasar Gracián en su famosa obra El Criticón llevaba a cabo una profunda reflexión sobre la naturaleza humana en la que censuraba el ser social de su tiempo y proponía como remedio de todos los males la educación conductora hacia la virtud. Otros teóricos representativos del período fueron J. Locke y F. Fénelon, preocupados por la formación de las clases altas rectoras. Sobre la influencia de Locke para entender el proteccionismo que hoy rige la mayoría de las políticas socioeducativas en las que se reconoce a la infancia como personas dependientes, pero con derechos propios, ver Morente Mejías, 2012.
}

cia hasta casi trescientos años después (Rabecq, 1957: 6), coincidiendo en el tiempo con la publicación de la obra de Philippe Ariès L'enfant et la vie familiale sous l'ancien régime (1960); son los años en los que, como se ha dicho, la infancia adquiere cierta autonomía como objeto de conocimiento historiográfico.

2.4. Conocer al niño para juzgar al hombre, desde la psicología a la moral infantil

Hacia finales del siglo XVII según señala Philippe Ariès se produjo una profunda transformación en los hábitos de vida cotidianos que se venía gestando desde siglos atrás, y que tuvo su eclosión en el siglo XVIII. Pareja a la implantación del nuevo orden burgués, cesó la cohabitación del niño con los adultos y la institución escolar reemplazó al aprendizaje como medio de educación, al tiempo que la familia se convertía en un lugar de afecto necesario donde adquirían valor todos y cada uno de sus miembros (Ariès, 1992: 11-12). La frialdad de siglos anteriores experimentada en las relaciones familiares fue ahora sustituida por nuevas costumbres donde el aprecio y la estima ocupaban un lugar destacado (Shorter, 1975), y donde aparece una concepción amorosa del matrimonio y de la familia como unión sentimental ${ }^{19}$. Surge una necesidad de intimidad y también de identidad en la que los miembros de la familia moderna se reúnen por sus sentimientos, sus costumbres y estilos de vida. La aparición de este nuevo espíritu doméstico se enmarcaba en un fenómeno mayor que comprendía la concepción de la familia nuclear como una unidad aislada del mundo exterior, que vivía en un hogar cerrado (Fontana, 1999: 57) ${ }^{20}$. Si bien durante los siglos precedentes la edad infantil y su aprendizaje se habían desenvuelto mayoritariamente en el marco de la comunidad, casi como una función espontánea de la sociedad en completa libertad, a partir de ahora, el retraimiento de las solidaridades comunitarias y sobre todo la expansión de las instituciones escolares como mecanismos educativos específicos, impusieron una nueva visión propia de la infancia que se iría transformando conforme la sociedad se dividía en clases y se delimitaban de forma precisa las funciones correspondientes a cada cual.

Junto a todo esto, se produjo la formación de otro nuevo sentimiento, serio y auténtico, "que ha inspirado toda la educación hasta el siglo XX, tanto en la ciudad como en el

\footnotetext{
19 Julia o La Nueva Eloísa de Rousseau publicada en 1761 representó una firJulia o La Nueva Eloísa de Rousseau publicada en 1761 representó una fir-
me defensa del matrimonio por amor que dio origen a la literatura lacrimógena posterior. Claramente la novela reflejó bien la concepción burguesa del matrimonio que se impondría a partir de este momento, como unión basada en las pasiones y sentimientos y no en las necesidades y obligaciones.

20 No pudiendo soportar el contacto con el pueblo, la burguesía se retiró para organizarse por separado, en un medio cerrado, conformado por viviendas construidas para la intimidad, en barrios nuevos protegidos de la contaminación popular. Se establece una relación entre comodidad e intimidad, que acentúa el antagonismo entre los ricos que se encierran en su vida privada y los pobres que conservan costumbres de vida en común.
} 
campo, en la burguesía y en el pueblo", el cariño hacia la infancia comenzó a expresarse en clave psicológica y moral (Ariès, 1992: 185). Surge un esfuerzo generalizado por conocer la mentalidad del niño para adecuar mejor a su nivel de desarrollo y a sus intereses y motivaciones los métodos educativos, buscando conciliar el afecto con la razón. Es así como se entiende y contextualiza la aparición del clásico tratado Emilio o De la Educación de Rousseau en 1762. Para el polifacético ginebrino la educación era concebida como un proceso natural ajustado a los intereses, necesidades y motivaciones del niño, sin forzar ni dominar su voluntad y adecuándolo a sus ritmos de desarrollo. Sin embargo, quizá convenga matizar aquí que este nuevo sentimiento y atención psicológica y moral hacia la infancia, aún con posibilidad de contemplarlo de forma general, tendría un impacto diferente en función del estamento social. A este respecto se apenaba Pestalozzi de las pobres madres que, movidas por la dureza y la dificultad extrema de mantener a sus hijos, abocaban en el abandono o el infanticidio (Sobre legislación e infanticidio, 1780-1783). No se trataba de falta de amor ni cariño, se trataba, a ojos del pedagogo suizo, de una realidad social lamentable y de la existencia de unas leyes inadecuadas y desiguales. Su bondad, ciertamente, sufría con la suerte de los explotados, sobre todo con la de los campesinos, pero también es cierto que, en acuerdo con las convicciones generales de su tiempo, aceptaba la existencia de un orden social asimétrico y nunca se propuso otra cosa que "educar a los pobres para que aceptaran de buen grado su pobreza" (Natorp, 1931 en Ponce, 2015: 145). El apóstol de la enseñanza popular, aunque partidario de la Revolución Francesa como justo castigo a los errores de los nobles, estaba convencido de la existencia de un orden social divino que debía mantenerse tal cual y que aceptaba tantos hombres y tantas educaciones como estratos sociales había. La educación para Pestalozzi debía contribuir a un desarrollo humano de las clases bajas digno y honrado, pero en última instancia, una educación que no perturbase la estructura social existente ${ }^{21}$. Análogamente, el abate Terrisse defendía el derecho de los campesinos a la instrucción como medio para mejorar sus condiciones de vida, pero también como medio de aculturación de los preceptos religiosos y sociales de los sectores elitarios (en Examen de la question s'il est utile ou prejudiciable au bien de l'État que les gens de la champagne sachent lire et écrire, 1746). Con una actitud menos condescendiente para su época, Helvétius afirmaba "todos nacemos iguales, luego, las desigualdades sociales, nacionales, culturales, sexuales, etc. son el producto de una educación discriminatoria e injusta", la educación era para el filósofo francés sinónimo de circunstancias, pero también las circunstancias, afirmaría Marx después, son producidas por el hombre y por tanto susceptibles de cambiar (Barreiro Rodríguez, 1987: 167). Para Helvétius "todo lo que no recibimos al nacer -como también decía Rousseau- se lo debemos a la educación" y tal era su importancia, que la concibe como cuestión de Estado. La infancia debía ser asistida y protegida por los poderes públicos que debían velar por su educación como mecanismo liberador que todo lo puede.

21 Sobre la figura de Pestalozzi interesa consultar su biografía: Guillaume (1927) y las obras de Natorp (1931) y Wickert (1936).
Claramente uno de los grandes logros de ciertos sectores del movimiento ilustrado fue situar en primer plano el análisis de las características y la función del fenómeno educativo contemplado desde la más tierna edad. Así, durante el siglo XVIII se observa cómo la atención, el cuidado y el aprecio por la infancia y todo lo que compete a la misma adquiere cada vez más relevancia en cualquier actividad de la vida social. Los avances en salud por la mayor disponibilidad de alimentos y por las mejoras higiénicas que propiciaron el espectacular aumento demográfico de mediados de siglo, repercutieron lógicamente en la infancia. La creciente densidad de la población requirió inevitablemente "lazos más estrechos en el interior y frente al exterior" (Engels, 1884/2017: 89). Con el objetivo de inculcar "buenos hábitos de vida" comenzaron a proliferar manuales divulgativos de higiene privada, "de «medicina doméstica» (aunque para un grupo selecto, culto y lector), cuyo fundamento teórico hundía sus raíces en la doctrina galénica" (Moreno Martínez, 2009: 25)22. Esta preocupación "alcanzó particular intensidad, tanto en escritos pedagógicos y médicos, como en las prácticas sociales en lo que se ha dado en llamar el impulso higienista del siglo XVIII" (Bolufer Peruga, 2000: 27) que, por supuesto, también llegó a las escuelas ${ }^{23}$. La educación se convirtió en uno de los grandes tópicos del siglo en tanto los ilustrados concibieron sus efectos como estímulos para avivar las luces del progreso y como un camino hacia la perfectibilidad humana, eso sí, de un público restringido y socialmente distinguido.

En este contexto el citado Emilio o De la Educación de Rousseau es considerado uno de los escritos más representativos del período, llegándolo a calificar algunos como una obra trascendental en la pedagogía occidental (Delgado Criado, 1998: 141). La idea básica de Rousseau fue concebir el amor, el apego y la ternura como elementos clave para el crecimiento humano y para el desenvolvimiento del niño y su maduración personal, posiblemente evocando un modelo educativo anhelado en su formación, aunque frustrado por parte de su estricto padre. El reconocimiento de la infancia como una etapa específica en sí misma y diferenciada de la adultez aparece presente en el Emilio, al igual que el concepto de libertad y lo que actualmente se da en llamar refuerzo positivo (Rousseau, 1990: 108).

Con Rousseau se redescubre la infancia, desde una mirada centrada en el niño, al que se observa como una criatura idealizada, irracional pero inocente, la cual por su fragilidad requiere cuidados y protección. La burguesía de la época prometía a través de Emiliola educación del hombre total, liberado y pleno ${ }^{24}$ (Ponce, 2015). Sin embargo, y

\footnotetext{
22 En este contexto se intensificaron también las publicaciones en defensa de la lactancia materna como el mejor y más sano alimento procurado a la infancia. Este hecho reforzaba los lazos entre madre e hijos, pues a partir de ahora las madres y no las nodrizas comenzaron a asumir la responsabilidad de la lactancia. Así la relación madre- hijo anteriormente poco valorada, adquiría una nueva fuerza (Fontana, 1999: 57).

23 Aunque el origen de la higiene escolar se produjo a finales del siglo XVIII con los aportes del médico austriaco J. P. Frank, su desarrollo e institucionalización a través de la creación de los servicios médico-escolares, comenzaría a darse a partir de la segunda mitad del siglo XIX (Moreno Martínez, 2009: 27).

24 Valga anotar aquí que en este contexto la concepción de ciudadano libre es la del hombre occidental de clase burguesa, no las mujeres, ni los siervos, ni los trabajadores, ni por supuesto los bondadosos habitantes de los incivilizados países de ultramar.
} 
aun considerando la repercusión de la obra y las críticas y controversias que generó, es difícil pensar que sus enseñanzas y exhortaciones llegasen a un público amplio, menos culto e instruido que el de sus habituales lectores. De igual modo y durante mucho tiempo sus consejos y recomendaciones no ejercieron gran influencia sobre los educadores ni sobre los padres, convencidos de las virtudes del ejercicio y del esfuerzo (Ariès, 1986: 16).

A pesar de la citada transformación en los sentimientos, aún habrá que esperar bastante para que la infancia, independientemente de su condición social, sea concebida como una etapa propia merecedora de una atenta educación, derechos, protección y cuidados. La derogación a fines del XVIII de algunas disposiciones que velaban por la infancia más desfavorecida y suprimían la ley de ilegitimidad por la que se condenaba públicamente a los expósitos negándoles el acceso a una profesión digna al no poder "certificar" su limpieza de sangre, únicamente puede entenderse en un contexto que iniciaba su andadura hacia una nueva formación social, el capitalismo, un sistema económico en el que para enriquecerse y crecer se requería abundante mano de obra barata y fácilmente maleable. La infancia de los pobres, percibida como un tiempo de adaptación a los hábitos de trabajo incluiría a partir de ahora cierta escolaridad supeditada a una función preparatoria para el desempeño de las faenas en la edad adulta (Cunningham, 1999: 252).

2.5. El niño es el padre del hombre, hacia las nuevas ciencias de la infancia y su representación social

La revolución industrial que inauguraba el largo siglo XIX operada en el país inglés como pionero y cuyos orígenes comenzaron a gestarse mucho antes, conllevó importantes transformaciones en la estructura social y demográfica de la época. Señala deMause (1982) adelantándose a la famosa publicación The Century of the Child de Ellen Key (1900), que el siglo XIX fue el siglo de la infancia, los padres comenzaron a interesarse de forma sistemática por sus hijos y existió una clara preocupación pedagógica por su protección, que superaba el modelo caritativo y benéfico de los siglos precedentes. Los tratados pedagógicos se centraron básicamente en la socialización y se produjo un desarrollo notable por parte de los Estados, de políticas sanitarias y sociales conducentes a prevenir o paliar las nefastas consecuencias sobre la salud y la vida derivadas de los extraordinarios cambios sobrevenidos (Moreno Martínez, 2009: 26).

El contexto es determinante en estos nuevos planteamientos, los años comprendidos desde 1800 a los principios del siglo XX, vienen marcados de forma profunda por importantes transformaciones en la vida de las personas, el fin de las estructuras del Antiguo Régimen y la entrada en la modernidad conllevó la consolidación de nuevas clases sociales, nuevas formas de trabajo, un nuevo sistema económico, nuevas formas de gobernar, la extensión plena de los sistemas educativos formales y en definitiva, nuevas formas de vivir, ver y sentir el mundo donde las relaciones en el marco de la familia se afianzaron y adquirieron un nuevo valor y donde la infancia ocupaba un lugar destacado.

Efectivamente la infancia se hizo plenamente visible ahora, las aportaciones y proyectos desarrollados por muchos de los nombres arriba citados y la difusión de las escuelas infantiles, los jardines de infancia, el reconocimiento del valor educativo del juego ofrecido por Friedrich Froebel, la renovación pedagógica del movimiento de la Escuela Nueva, un acercamiento más sensible, global y fundamentado hacia la infancia por parte de María Montessori y Ovide Decroly, contribuyeron en gran parte. También, y de forma paradójica, su visibilidad devino igualmente y como ya se ha dicho, por la urgente necesidad de mano de obra asequible y dócil para la incipiente industria. El trabajo infantil no fue ahora una novedad, pero si antes se realizaba como una tarea más, ligada a la economía doméstica, suplementaria a la misma y en un ámbito de cierta proximidad al hogar, las condiciones y características en este momento sí cambiaron, los hijos de los pobres constituían ahora un valor económico para sus padres. Los niños y niñas más desamparados, al igual que sus madres, podían utilizarse como fuerza de trabajo barata y obediente en un sistema económico que absorbía sus horas y sus vidas. Aunque desde los primeros años del siglo XIX en el contexto inglés y de forma casi paralela al desarrollo industrial, fue gestándose toda una normativa que limitaba y en casos prohibía el trabajo infantil, la efectividad de tales normas fue en muchos casos dudosa. Todavía en los años centrales del siglo XIX Marx se lamentaba de la triste situación de los niños en las fábricas inglesas y de sus miserables condiciones de trabajo al tiempo que Dickens publicaba su novela más autobiográfica David Copperfield, prototipo de la infancia más desamparada. Si bien en Marx el concepto de niño rebasa la edad que aquí otorgamos a la infancia, e igualmente los niños obreros a los que se refería hacía ya tiempo que habían superado la infancia, si es que alguna vez la habían tenido (Delgado Criado, 1998: $187)$, es muy interesante conocer sus denuncias sobre la manufactura de fósforos donde la mitad de los obreros son niños que no han llegado a los 13 años. Anotaba Marx en el capítulo sobre "La jornada laboral" citando los informes de la Comisión de Empleo Infantil de 1863 “Esta manufactura, por su insalubridad y repugnancia, está tan desacreditada que solo la parte más desmoralizada de la clase obrera, las viudas medio muertas de hambre, le suministran niños zaparrastrosos, famélicos, completamente desamparados e incultos" (Marx, 2018 p. 43). Como ya apuntó Jens Qvortroup la infancia se hallaba expuesta a las mismas adversidades que los adultos, aunque de una manera muy particular, sujeta a las condiciones reales de su edad temprana (Qvortroup, 1999). En el caso español no faltaban tampoco ejemplos, tales como las abyectas condiciones reflejadas en los escritos del médico catalán Pere Felip Monlau en los que aparecen niños de entre 7 y 8 años trabajando un total 
de 10 o 12 horas (Delgado Criado, 1998: 178), o el trabajo infantil en las minas del sureste que fue una constante hasta bien avanzado el siglo $X^{25}$.

La socialización de la infancia de la que empezaron a ocuparse los tratados pedagógicos a partir de ahora, interesaba en la medida en que proliferaban los espacios para ello, tanto el entorno laboral primero, como el escolar después y el propiamente lúdico.

En 1816 guiado por ideales de reforma social y tras hacerse cargo de la gestión de New Lanark, imponente centro fabril de hilado en Escocia, el industrial socialista utópico Robert Owen fundó la que sería conocida como primera escuela infantil, Infant School, destinada a niños y niñas hasta los seis años de edad, considerados demasiado pequeños para trabajar, pero suficientemente mozos para formar su carácter y cuyos padres debían atender al trabajo. Este modelo de escuela inglesa se convirtió en un importante referente para otros países del entorno que fundaron también escuelas infantiles, aunque con diferente éxito según cada caso ${ }^{26}$. Además, no debe olvidarse que el incipiente desarrollo industrial del siglo requería una mano de obra cada vez más especializada y cualificada (siguiendo el modelo de la división técnica del trabajo inspirado en Adam Smith) capaz de manejar bien las cada vez más sofisticadas y complejas máquinas. Por tanto, sin menosprecio de las ideales concepciones del socialismo utópico de la época partidario de la mejora de las condiciones de la clase trabajadora, una adecuada, diligente y temprana instrucción era sin duda un magnífico aliciente para el crecimiento económico.

Claramente, el interés familiar sistemático de las familias apareció en el marco de la incorporación de la mujer al mundo laboral y la necesidad de crear espacios para el cuidado y custodia de los más pequeños; la preocupación pedagógica por su protección y educación, obedeció posteriormente a la proliferación y difusión de una amplia literatura pedagógica que ponía en valor el modo de conocer y abordar el mundo infantil y lo consideraba desde un punto de vista científico como una etapa fundamental.

Indudablemente, la eclosión de nuevas corrientes científicas durante el siglo XX transformó de forma profunda la concepción sobre la infancia, configurando en palabras de Cunnigham "una ideología de la infancia" devenida por su sacramentalización y sentimentalización:

Cuanto más la sociedad de los adultos se mostraba fría, urbanizada y alienada, más la infancia era vista como un jardín que encerraba en la seguridad de sus muros, un modo de vida que se correspondía con la naturaleza y que preservaba las rudas virtudes de los primeros períodos de la historia de la humanidad (Cunningham, 1999).

\footnotetext{
25 Una síntesis sobre los principales trabajos y estudiosos del tema del trabajo infantil en España puede consultarse en Ruíz Rodrigo, 2009. Merecen especial atención sobre este tema las publicaciones del profesor José María Borras Llop. 26 Es interesante seguir su evolución en Francia con la fundación de las salas de asilo conocidas después como escuelas maternales; en España con las escuelas de párvulos fundadas por Montesino, en Alemania, Italia, Bélgica, Holanda, Hungría Suecia, Suiza e incluso en EE. UU (para un estudio detallado de algunos casos ver Sanchidrián Blanco y Ruiz Berrio (2010).
}

Desde la paidología, constituida como ciencia del niño, a la pediatría en sentido amplio, la psicología, la psicopedagogía o la psicometría, ocupada de medir la capacidad mental, al psicoanálisis, la visión de la infancia ha cambiado sustancialmente ${ }^{27}$. El concepto de infancia se construye de este modo como una categoría social, variable y temporal, y con carácter cultural que se dota de teoría y que adquiere su sentido en función del contexto histórico.

El siglo XX es también el que ve nacer a nivel jurídico todo un corpus legislativo protector de la infancia, sobre todo y en primer término de aquellos niños y niñas cuyas vidas quedaban muy alejadas del ideal de infancia ya gestado. Los problemas que afectaban a la infancia fueron concebidos desde la vertiente del derecho como síntomas de la decadencia social que necesariamente debían erradicarse. El 24 de septiembre de 1924 la Sociedad de Naciones adoptó como propia la que puede considerarse primera Declaración de los Derechos del Niño concebida en el seno de la Alianza Internacional Save the Children fundada por Eglantyne Jebb y su hermana Dorothy Buxton en 1919, tras la Primera Gran Guerra. Dicha Declaración, a partir de entonces, Declaración de Ginebra, recogía toda una serie de derechos específicos para los niños y las niñas y pautas de conducta a seguir en cuanto a su cuidado. También en las primeras décadas del pasado siglo destacaron los estudios del polaco Janusz Korczak, defensor de una comprensión de los derechos de la infancia como motor del cambio social y como una contribución necesaria para rediseñar las relaciones generacionales y reconocer su protagonismo (Liebel, 2019).

Tras la Segunda Guerra Mundial y como consecuencia de los efectos derivados y del elevado número de menores huérfanos y desprotegidos que dejó el conflicto, la Asamblea General de Naciones Unidas aprobó el 20 de noviembre de 1959 la Declaración de los Derechos del Niño, conmemorándose el citado día como Día Mundial de la Infancia. Posteriormente, la Convención sobre los Derechos del Niño de 20 de noviembre de 1989 aprobada por Naciones Unidas ${ }^{28}$ reconocía a los niños como ciudadanos de pleno derecho con posibilidad incluso de expresar sus puntos de vista. Continuadores de esta legislación se irían aprobando posteriormente diversos planes y programas que integraban a la infancia en sus líneas estratégicas de trabajo con distintas visiones sobre la misma ${ }^{29}$.

La infancia, cada vez más, será percibida como una etapa determinada de la vida con su propia dinámica y su propia cultura que además posee el poder de moldear y determinar la vida del adulto (Cunningham, 1999).

El niño ya no ocupa un lugar marginal en la familia y en la sociedad, existe con entidad propia y aún más, con el espectacular aumento de la sociedad de consumo, en el marco de una economía capitalista y a partir de los avan-

\footnotetext{
27 Señala Ariès que de hecho fue el psicoanálisis y su rápida divulgación en los treinta primeros años del siglo XX, lo que llevó al éxito las propuestas educativas de Rousseau (1986: 16).

28 Fue ratificada por todos los países excepto Omán, Somalia, Suiza, Emiratos Árabes, EEUU y algunos más (Delgado Criado, 1998: 208).

${ }^{29}$ Igualmente, los movimientos en favor de los derechos de la infancia han sido múltiples y diversos, destacan por su representatividad en el ámbito norteamericano el "child liberationism" liderado por J. Holt y R. Farson y el "child protectionism" guiado por $\mathrm{H}$. Foster.
} 
ces producidos por las ciencias descritas y otras tantas en su conocimiento, se diseña toda una compleja estructura marketinista a su servicio, que en cierto modo diluye las fronteras con la adultez. En occidente o en cualquier otro lugar del mundo donde el poder adquisitivo lo permita, el niño es ahora un potencial consumidor y el afecto hacia el mismo ha trasmutado en muchos casos en una especie de esencialismo material; desde que nace a través de los padres con toda una gama de productos y servicios de cuidado y crianza, hasta los años en que va adquiriendo autonomía propia donde define su autoestima en función de sus posesiones y ejerce además una influencia decisiva sobre las decisiones de compra de sus progenitores. Muchos padres entienden las elecciones infantiles entre un amplio catálogo de opciones como "oportunidades de aprendizaje" (Schor, 2006: 37) y de libertad de preferencias, pero es un hecho evidente que la exclusiva satisfacción material de sus deseos, en muchos casos creados con la condescendencia de los adultos y la mera sustitución del apego por el materialismo, no es sinónimo de interés y cariño. La reproducción social en las nuevas sociedades de mercado terminaría acosada pero también seducida por un consumo irracional de satisfacciones. Las consecuencias de los asombrosos cambios sociales pueden ejemplificarse con la presión social ejercida sobre las familias, definidas ahora por su capacidad de consumo. Como ha escrito el sociólogo alemán Wolfgang Streeck, al mismo tiempo que "los hijos "de calidad" aprenden chino a los tres años en la escuela infantil, sus padres "de calidad" trabajan largas horas para poder pagar el cuidado "de calidad" de sus hijos que ellos no tienen tiempo de proporcionar y el todoterreno que necesitan para el tiempo "de calidad" que pasan con sus retoños durante sus -raros- fines de semana libres" (Streeck, 2017: 259).

La contemporaneidad esboza una imagen opaca de la infancia, su mercantilización, junto a la visión del niño como entelequia del adulto, la creciente protección jurídica, su reciente participación ciudadana y una posible desafección del sentimiento intuida por Ariès (1986), se mezclan en un mundo donde todavía existen millones de niños y niñas cuya infancia continúa siendo casi imperceptible. Muchas de las condiciones infantiles descritas a principios del siglo XIX se mantienen aún vigentes y aunque no es una circunstancia universal, la infancia no goza en todo el mundo de igualdad plena, de protección a su desarrollo y crecimiento, de reconocimiento de su identidad, de una alimentación, vivienda y atención médica adecuados, de una educación y atención especial ante cualquier discapacidad, de comprensión y amor de los padres y de la sociedad, de tolerancia, del goce de actividades recreativas, de prioridad asistencial, de defensa contra el abandono, o contra la crueldad y la explotación. Parece ser que las cosas no van como se esperaba. Según el informe de la FAO (2019) el hambre, la inseguridad alimentaria y la malnutrición infantil unida a la marginación social, los conflictos y la inestabilidad climática y sus fenómenos derivados, han desencadenado consecuencias nefastas para la infancia y para toda la población. Aunque el "Informe mundial sobre la infancia 2019: 'Infancias robadas"' publicado por Save the Children señala una mejora en la vida de los niños y niñas en los últimos 20 años, todavía 1 de cada 4 no goza de una infancia segura y sana, cada día casi 15.000 niños y niñas mueren antes de cumplir 5 años por causas evitables, 262 millones de niños y niñas no tienen acceso a la educación y cada minuto más de 20 niñas o adolescentes son obligadas a casarse contra su voluntad. En palabras de Göran Therborn:

Las posibilidades de supervivencia de aquellos que nacen entre el 20 por 100 más pobre del mundo son solo la mitad de las de quienes nacen en el quinto más rico. En India, casi la mitad de la población sufre retrasos en el crecimiento físico y mental durante la niñez, un problema del que muchos no llegan nunca a recuperarse del todo. También en Gran Bretaña, la impronta de clase en los bebés es ya visible a la edad de veintidós meses. En este sentido, la desigualdad es tal vez el mayor "crimen contra la humanidad" (2017: 69).

Las desigualdades económicas, sociales, políticas, culturales, geográficas, familiares y de todo tipo, presentes en el mundo de hoy, y posiblemente más insondables que en las épocas que aquí hemos recorrido, afectan lógicamente a la infancia.

Si la revelación más intensa del alma de una sociedad es la forma en que trata a su infancia, debemos concluir en la necesidad urgente de remedios públicos efectivos y reales. Pero no solo eso. Transformar el mundo requiere nada menos que cambiar desde sus mismos cimientos las condiciones que generan y al mismo tiempo sustentan todo el campo de las desigualdades contemporáneas.

\section{Conclusiones}

Tal y como se ha puesto de manifiesto a lo largo del presente trabajo, las ideas y el interés por la educación y la crianza de los niños y niñas más pequeños han ido variando a lo largo de las diferentes etapas históricas y adecuándose a los cambios experimentados por las familias, condicionados éstos por importantes procesos de orden político, social, económico, demográfico y cultural. Así, cada contexto societal y cultural ha ido reconfigurando la noción de infancia imperante en cada momento histórico, sus peculiaridades y hasta la edad de las personas que incluye. Hasta tiempos relativamente recientes, no se reconocía la infancia como una etapa diferenciada con sus propias características y cualidades, el niño era concebido como un adulto en miniatura sin tener en cuenta su evolución, sino más bien el cambio desde un estado inferior a otro superior. Aunque con algunas particularidades, "la concepción que se tenía del niño según los primeros registros del pensamiento racional viene inspirada por distintas creencias y tradiciones culturales que comparten una misma noción del ser humano, representado en la persona adulta" (Morente Mejías, 2012: 241). Hasta el siglo XVII no 
hubo un sentimiento y reconocimiento de la infancia, ni una educación pensada y adaptada a esta etapa de la vida. La nueva función moral y espiritual asumida por la familia contribuyó a la aparición del sentimiento moderno de familia y a intensificar la individualidad de cada uno de sus componentes. A partir de entonces, el reconocimiento y el interés manifiesto por la naturaleza infantil de varios pensadores, sentaría las bases para el estudio y preocupación por la educación infantil desarrollándose la casi totalidad "de las teorías y prácticas a favor de la identidad social de la infancia, en interacción con los imaginarios sociales hegemónicos de las sociedades modernas" (Morente Mejías, 2012: 240). Además, la aceleración de los cambios de tipo político, social, económico, demográfico y cultural acaecidos en el tránsito hacia la modernidad, influirían en la necesidad de su instrucción desde edades tempranas.

Ciertamente, el hombre occidental experimentó a lo largo de los siglos XVIII y XIX una revolución en la afectividad que, lo hicieron diferente, no mejor, únicamente distinto "sus sentimientos se subdividen de otro modo, $y$, en particular, se concentran más en el hijo" (Ariès, 1986: 16), lo cual no significaba falta de amor hacia el mismo en épocas anteriores, los padres siempre, a lo largo y a lo ancho, amaron a sus hijos (Cunningham, 1999; Pollock, 1990). Quizá más bien la pérdida de valor productivo de la infancia derivada de una contención legislativa que vetaba el trabajo infantil conllevó una mayor concentración emocional. Las transformaciones en las pautas demográficas y sociales, relaciones familiares y formas de vida tales como el crecimiento y ampliación de los núcleos urbanos, la incorporación de la mujer al trabajo, la reducción de los miembros de la unidad familiar unida al control y planificación de la gestación, o la reducción del tamaño de los hogares, entre otros muchos, promovieron un contacto más estrecho entre padres e hijos modelando de forma gradual y progresiva un tipo de familia donde las relaciones de interacción entre sus miembros adquirían un valor esencial. Al tiempo y en paralelo, dejó de resultar extraño que otros fuesen asumiendo funciones que antes habían sido parte del orden familiar, o incluso de la comunidad, como, por ejemplo, trasladar la responsabilidad de cuidado a las guarderías y jardines de infancia públicos (Hobsbawm, 1994: 341). Claramente en medio de este nuevo orden social transformado, los viejos valores comunitarios y familiares y las tradiciones y usos que habían regido durante siglos el comportamiento humano cambiaban de forma profunda. Las transformaciones en la convivencia y comportamientos de la familia resultaban evidentes, y la infancia no permanecía al margen.

En su obra Breve historia de la infancia (1998) Fe Bajo y José Luís Beltrán distinguieron dos mundos infantiles que se distanciarían de forma irremediable entre los siglos XVI y XIX: los niños que jugaban y los que no tenían tiempo para jugar, los que tenían juguetes y los que no, los que iban a la escuela y los que trabajaban... evidenciando un fenómeno que se extendería hasta el presente, "la existencia de una infancia en el discurso que corresponde a la realidad de solo una parte de niños y niñas y la existencia de otra infancia también real, en condiciones similares o peores a las descritas en otros periodos históricos" (Duran Strauch, 2015: 9). Una nueva visión sobre la infancia, se impondría durante todo el siglo XX basada en una "normalidad" ajustada a la libertad y a la moral burguesas, tal como planteó Foucault, y que legitimaba la intervención de profesionales sociales, sobre todo en la vida de las familias más pobres, para evitar los problemas físicos, morales y sexuales. La desigualdad y la exclusión se integraban en el vocabulario de muchas de las ciencias afines a la infancia y frente a lo que debería ser natural, continúan en nuestros tiempos.

Desde una esfera de casi invisibilización o cierta posición secundaria a nivel familiar, por la que hemos transitado en el estudio, se ha pasado a un estado donde la infancia ocupa un lugar central tanto en el espacio privado como público, en el político y normativo hasta el espacio económico y social, con toda una gama de servicios y productos destinados a la misma, y con una clara conciencia en la que prima su cuidado, seguridad y educación. Sin embargo, como se ha puesto de manifiesto en las líneas precedentes existen profundos contrastes en el mundo de hoy, la disociación entre el discurso sobre la infancia que abarca los ámbitos del derecho, de la política, la psicología, la pedagogía y la medicina y las condiciones reales de existencia de millones de niños y niñas en todo el mundo, parecen cada vez mayores. Recientes investigaciones en epigenética y desarrollo infantil han demostrado la relación entre la esperanza de vida humana y los entornos sociales fetales y posnatales. "Cada vez resulta más claro que los humanos nacen desiguales y que la desigualdad general se acelera durante el curso de sus vidas" (Therborn, 2017: 86). Frente a una infancia ideal de clases medias y altas representativa de la bucólica aventura del conocimiento que propuso Rousseau, otra infancia compuesta por millones de niños y niñas cuyos años inocentes transcurren en medio de desnutrición, violencia o enfermedades prevenibles, como una pesadilla llena de carencias y problemas (Duran Strauch, 2015: 15). La pobreza, la marginación y la explotación de los niños y niñas no solo perviven en el mundo de hoy, sino que se constituyen en lacras progresivamente crecientes que afectan de forma general a todos los países, tanto a aquellos considerados menos desarrollados como a los que han alcanzado un mayor despliegue industrial (Ruíz Rodrigo, 2009: 537). Aunque la existencia de la infancia pueda transitar sin dejar aparentemente ninguna hueIla, como sujetos indescifrables y silenciosos, su papel en la historia ha sido y es determinante. 
Fuentes y Bibliografía

\section{Fuentes clásicas}

ARISTÓTELES, Política. Capítulo XV, Libro IV.

CICERÓN, Del Orador

PLATÓN, República, VII, Obras completas, ed. de Patricio de Azcárate. QUINTILIANO, Instituciones Oratorias, Capítulos I.I.- I.IV. y II.II. SEVILLA, de I., Etimologías.

TEODOSIO II, Código Teodosiano, VI, I, I.

\section{Informes}

ORGANIZACIÓN DE LAS NACIONES UNIDAS PARA LA ALIMENTACIÓN Y LA AGRICULTURA, FAO (2019): El estado de la seguridad alimentaria y la nutrición en el mundo. Protegerse frente a la desaceleración y el debilitamiento de la economía. https://www.fao.org/3/ca5162es/ ca5162es.pdf.

SAVE THE CHILDREN (2019): Informe mundial sobre la infancia 2019: Infancias robadas.' https://www.savethechildren.es/actualidad/ informe-mundial-infancia-2019-infancias-robadas.

\section{Bibliografía}

ALZATE PIEDRAHITA, Ma V. (2004): "El “Descubrimiento" de la Infancia (I): Historia de un Sentimiento", Revista Electrónica de Educación y psicología, REPES, 1, pp. 1-11.

ARIÈS, P. (1986): “La infancia”, Revista de Educación, 281, pp. 5-17.

ARIĖS, P. (1992): El niño y la vida familiar en el Antiguo Régimen. BarceIona, Taurus.

BAJO ÁLVAREZ, F. y BELTRÁN MOYA, J. L. (1998): Breve historia de la infancia. Madrid, Peñalara.

BALLÉN MOLINA, R. A. (2010): "La pedagogía en los diálogos de Platón", Diálogos de Saberes, pp. 35-54.

BARREIRO RODRÍGUEZ, H. (1987): "La educación como cuestión de Estado de Platón a la ilustración francesa", Historia de la educación, 6, pp. 161-170

BARTHES, R. (2000): Mitologías. Madrid, Siglo XXI.

BECCHI, E. (1983): "Molte infanzie, poche storie", Ricerche pedagogiche, 68-69, pp. 1-15.

BOLUFER PERUGA, M. (2000): "Ciencia de la salud" y "Ciencia de las costumbres": Higienismo y educación en el siglo XVIII", Áreas. Revista Internacional de Ciencias sociales, 20, pp. 25-50.

BORRÁS LLOP, J. M. (coord.) (1996): Historia de la infancia en la España contemporánea, 1834-1936. Madrid, Ministerio de Trabajo e inmigración.

BOSSARD, J. (1948): The Sociology of Child Development. Nueva York, Harper International.

BURGESS, E. W. (reed. 1972): "The family as a unity of interacting personalities", en G. D. Erikson y T. P. Hogan (eds.), Family therapy: An introduction to theory and technique. Monterey, California: Brooks/ Cole, pp. 4-15.

BURKE, P. (2003): Formas de hacer Historia. Madrid, Alianza.

CARCOPINO, J. (1993): La vida cotidiana en el apogeo del Imperio. Barcelona, Planeta.
CARRILLO GARCÍA, G. (2020): "Transgresiones de la Historia. La misión pública de la historia y la dialéctica científica", Pasajes: Revista de pensamiento contemporáneo, 60, pp. 117-151.

COMENIO, J. A. (1998). Didáctica Magna. México, Ed. Porrúa. 1ª ed. 1657. CUNNINGHAM, H. (1999): “Los hijos de los pobres. La imagen de la infancia desde el siglo XVII", en Derecho a tener derecho. Infancia, derecho y políticas sociales en América Latina. Montevideo, UNICEF-IIN, vol. 3, pp. 251-256.

DEMAUSE, LI. (1982): Historia de la infancia. Barcelona, Alianza.

DELGADO CRIADO, B. (1998): Historia de la infancia. Barcelona, Ariel.

DELVAL, J. (1988): "Sobre la historia del estudio del niño", Infancia y Aprendizaje, 44, pp. 59-108.

DURAN STRAUCH, E (2015): "Construcción sociohistórica de la infancia moderna". http://aularedim.net/diplomado/docs/M1/M11.pdf. Fragmento del marco teórico de la tesis doctoral, Derechos del niño: del discurso a la política local, análisis del caso. Bogotá, Universidad Nacional de Colombia.

ESCOLANO, B. (1980): "Aproximación histórico-pedagógica a las concepciones de la infancia", Studia Pedagógica. Revista de Ciencias de la Educación, 6, pp. 5-16.

ESCOLANO, B. (1997) “La historia educativa. Tendencias generales”, en G. Narciso y A. Viñao Frago (eds.), La investigación histórico-educativa. Tendencias actuales. Madrid, Methodika, pp. 51-84.

FINKELSTEIN, B. (1986): “La incorporación de la infancia a la historia de la educación", Revista de educación, 281, pp. 19-46.

FONTANA, J. (1992): La Historia después del fin de la Historia. Barcelona, Crítica.

FONTANA, J. (1999): Introducción al estudio de la Historia. Barcelona, Crítica.

GARCÍA HERRERO, M. C. (1998): "Elementos para una historia de la infancia y de la juventud a finales de la Edad Media" en J. I. de la Iglesia Duarte (coord..), La vida cotidiana en la Edad Media: VIII Semana de Estudios Medievales: Nájera, del 4 al 8 de agosto de 1997. Logroño, Instituto de Estudios Riojanos, pp. 223-252.

GÉLIS, J. (2005): “La individualización del niño”, en P. Ariès y G. Duby, Historia de la vida privada, vol. 3 (Del Renacimiento a la llustración). Madrid, Taurus, pp. 293- 307.

GINZBURG, C. (1989): Mitos, emblemas, indicios. Barcelona, Gedisa.

GONZALBO AIZPURU, P. (2006): Introducción a la historia de la vida cotidiana. México, El Colegio de México.

GUILLAUME, J. (1927): Pestalozzi. Madrid, Ed. de la lectura.

HAZARD, P. (1960): Los libros, los niños y los hombres. Barcelona, Juventud.

HOBSBAWM, E. (1994): Historia del siglo XX. Buenos Aires, Grijalbo Mondadori.

HOBSBAWM, E. (2014): Sobre la historia. Barcelona, Crítica.

HOBSBAWM, E. (2016): "Pierre Bourdieu. Sociología crítica e historia social", New Left Review, 101, pp. 41-52.

LE GOFF, J. (1999): La Civilización del Occidente medieval. Barcelona, Paidós.

LE GOFF, J. y NORA, P. (1978): Hacer la Historia. Barcelona, Laia.

LENGBORN, T. (1993): “Ellen Key (1849-1926)", Perspectivas: revista trimestral de educación comparada, XXIII (3-4), pp. 873-886.

LIEBEL, M. (2019): "Janusz Korczak, los derechos y el protagonismo de la infancia", Revista Educación Social, 28, pp. 176-195.

MARTÍNEZ RUIZ FUNES, Ma J. (2013): La cultura material y la educación infantil en España: el método Froebel (1850-1939). Tesis doctoral, Universidad de Murcia.

MARX, C. (2018). “La jornada laboral”, en C. Marx, El Capital, Libro I, Cap. 8. Ed. digital Fundación Editorial El perro y la rana.

MORENO MARTíNEZ, P. L. (2009): “Presentación. Cuerpo, Higiene, Educación e Historia", Historia de la Educación, 28, pp. 23-36.

MORENTE MEJÍAS, F. (2012): "Visiones de la infancia y la adolescencia: notas para una concepción alternativa", Revista de Sociología de la Educación-RASE, 5 (2), pp. 240-257.

NATORP, Paul (1931): Pestalozzi, su vida y sus ideas. Barcelona, Labor. 
PONCE, A. (2015): Educación y lucha de clases. Buenos Aires, UNIPE.

POLLOCK, L. (1990): Los niños olvidados. Relaciones entre padres e hijos de 1500 a 1900. México, Fondo de Cultura Económica.

RABECQ, Ma M. (1957): “Juan Amos Comenius. Apóstol de la educación moderna y de la comprensión internacional", El Correo, Unesco, 11, pp. 4-16.

REMORINI, C. (2013): "Estudio etnográfico de la crianza y de la participación de los niños en comunidades rurales de los Valles Calchaquíes septentrionales (noroeste argentino)", Bulletin de I'Institut français d'études andines, 42 (3), pp. 411-433.

ROUSSEAU, J. J. (ed. 1990): Emilio o De la Educación. Madrid, Alianza.

RUIZ RODRIGO, C. (2009): "Trabajo infantil y educación: algunas claves historiográficas y documentales", en Ma Reyes Berruezo Albéniz y Susana Conejero López (coords.), El largo camino hacia una educación inclusiva: la educación especial y social del siglo XIX a nuestros días: XV Coloquio de Historia de la Educación, Pamplona-Iruñea, 29 de junio al 1 de julio de 2009. Pamplona, Universidad Pública de Navarra, vol. 2, pp. 537-548.

SANTOLARIA SIERRA, F. (1997): Marginación y educación: historia de la educación social en la España moderna y contemporánea. Barcelona, Ariel.
SANCHIDRIÁN BLANCO, C. y RUIZ BERRIO, J. (coords.) (2010): Historia y perspectiva actual de la educación infantil. Barcelona, Graó.

SCHOR, J. (2006): Nacidos Para Comprar: Los Nuevos Consumidores Infantiles. Barcelona, Paidós.

SHORTER, E. (1975): The Making of the Modern Family. Nueva York, Basic Books.

STEARNS, P. (2010): Childhood in World History. Nueva York, Routledge. STONE, L. (1986): El pasado y el presente. México, Fondo de Cultura Económica.

STREECK, W. (2017): ¿Cómo terminará el capitalismo? Ensayos sobre un sistema en decadencia. Madrid, Traficantes de Sueños.

THERBORN, G. (2017): "Dinámicas de la desigualdad", New Left Review 103, pp. 69- 89.

ULIVIERI S. (1986): "Historiadores y sociólogos en busca de la infancia apuntes para una bibliografía razonada", Revista de Educación, 281, pp. 47-86

WICKERT, Richard (1936): Historia de la pedagogía. Madrid, Ed. de la Revista de Pedagogía.

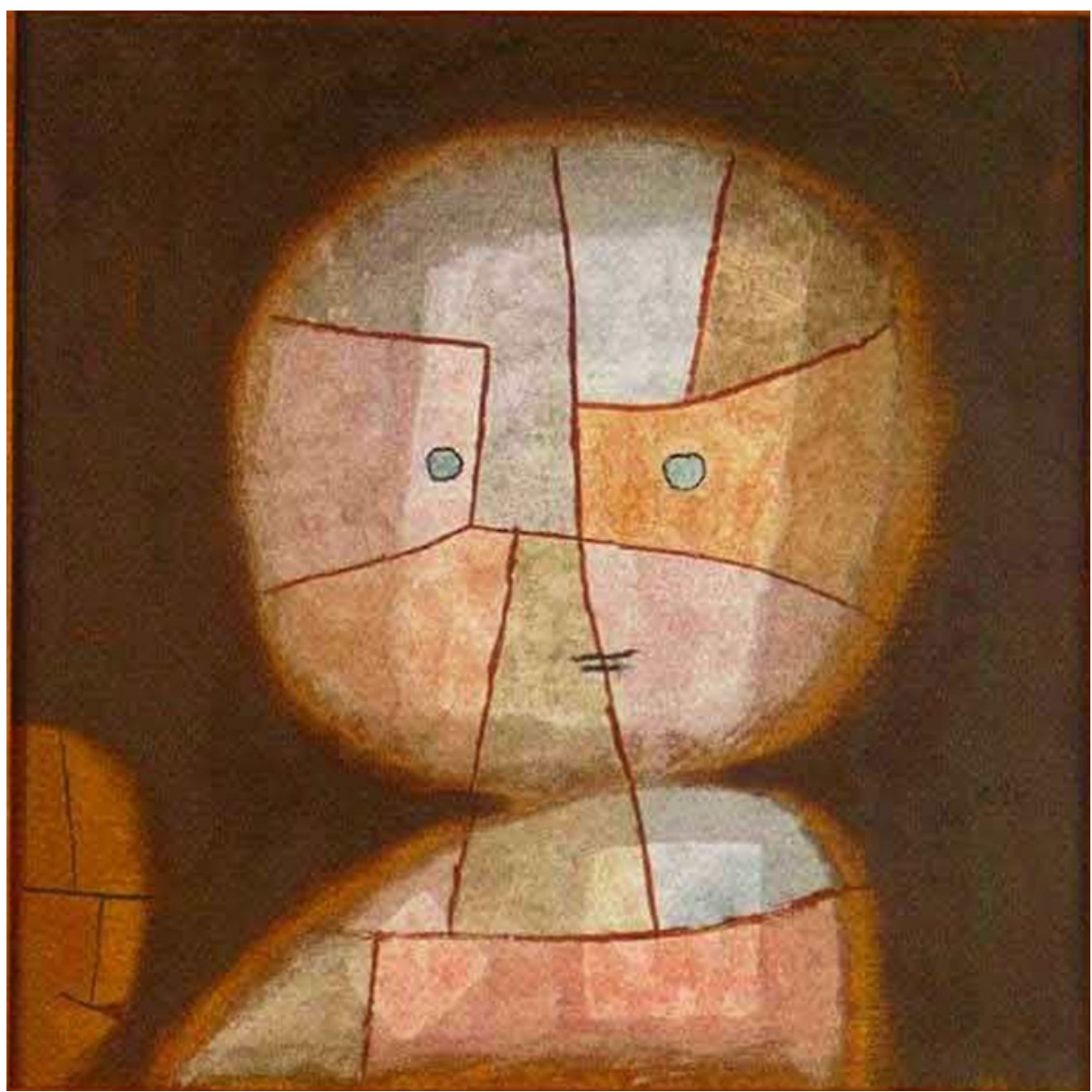

Paul Klee, Busto de un niño, 1933. Museo de Bellas Artes de Berna. Suiza. 